\title{
A Revolution Scheduled on a Facebook Page
}

\author{
Eman Mosharafa ${ }^{1}$ \\ ${ }^{1}$ Department of Humanities, LaGuardia C. C., City University of New York, New York, USA. \\ Correspondence: Eman Mosharafa, Department of Humanities, LaGuardia C. C., 31-10 Thomson Avenue, Long \\ Island City, N.Y. 11101. Email: emosharafa@lagcc.cuny.edu
}

Received: April 13, 2015

doi:10.11114/ijsss.v3i4.762
Accepted: April 29, $2015 \quad$ Available online: May 19, 2015

URL: http://dx.doi.org/10.11114/ijsss.v3i4.762

\begin{abstract}
January 25th, 2011 marks a momentous day for Egypt, and perhaps for the world. The revolution was the largest in the history of the country. What makes it unique is the integral role that social media played in mobilizing the masses. In particular, the "We are all Khalid Said" Facebook page served as the national communication corridor which prompted action. This manuscript examines the specific role of the Facebook page in mobilizing a critical mass. Through a detailed quantitative content analysis of the page's activity, the manuscript captures the granular online communications that lead up to the Egyptian revolution. Social mobilization theory is utilized to illustrate how the page was able to incite such mobilization. Results show that the administrators of the "We are all Khalid Said" Facebook page implemented a process with five key missions: 1) Creating an injustice frame, 2) Broadcasting activities of defiance, 3) Emotionally inflaming and inspiring people, 4) Engaging participants, and 5) Organizing a concerted action plan.
\end{abstract}

Keywords: Mobilization, Egyptian Revolution, Content Analysis, Social Media, Cyberactivism.

\section{Introduction}

The theoretical debate about whether social media is capable of inciting political action has been settled in light of the Egyptian revolution of January 25, 2011. Egyptian protestors were able to group and organize through means of online activism. Specifically, the Facebook page "We are all Khalid Said" was credited with mobilizing and organizing the majority of the protesters, acting as a major trigger for the revolution (Khamis and Vaughn 2011 a, P146). The page established the revolution as a scheduled event with a specific date, time, and locations, allowing protestors to solidify and overcome the challenge of critical mass formation. Through a detailed content analysis of the "We are all Khalid Said" Facebook page, this paper documents how the page embodied the conditions needed for inciting mobilization. Utilizing social mobilization theory, this paper highlights the culture mobilization theory, strategic intervention mobilization theory, resource mobilization theory, and social strain theory.

This research throws light on an important moment of media use and activism. It represents an illuminating case study on cyber-activism within the broader "Arab Spring." It is worth mentioning that the author of this paper was an active member of the "We are all Khalid Said" page since its inception in June 2010. She bore witness to the page postings in real time, and to the correlation of page members' correspondence and significant events, leading up to the revolution. She was also an active participant, who took to the street in the name of the January 25 Revolution.

\section{Political Context in Egypt}

Inspired by the Tunisian uprising and ousting of president Bin Ali, the political climate of Egypt was invigorated on January 25. The previous decade marked a high level of resentment to the Mubarak regime. In the few months leading up to the revolution, the brutality of the regime intensified. The conditions were escalated by fixed parliamentary elections, the brutal police killing of Khalid Said, the bombing of Saints Church on New Year's Eve, and the police killing of Sayed Bilal, who was accused of the bombing. The Egyptian people shared a feeling of general dissatisfaction, but there was a missing channel between public resentment of the ruling regime and actual public mobilization to bring about real change.

\subsection{The Challenge of Creating a Critical Mass}

Egyptian activist groups had been attempting to organize an uprising for almost a decade (Khamis and Vaughn, $2011 \mathrm{~b}$, P7). However, these disjointed movements were sporadic and had a limited scope of demands. They were thus unable to unite the voice of the Egyptian people or garner a critical mass. One example of these restrained movements is the " 9 
March Group" of 2003, in which tens of academicians formed the University Independent Group, commonly known as the 9 March Group, in order to end the intrusion of the Egyptian government into university affairs. Among their work, they filed a lawsuit against police deployment on campus (9 March Group, 2009). While the efforts of the 9 March Group are highly respected, the group's demands were limited to reforming higher education.

Other movements concentrated on changing Egypt's political system. For instance, the localized "Kefaya" or "Enough" movement in 2004 started a wave of protests against the renewal of President Mubarak's term or the election of his son. This movement was the first to organize political protests demanding the president step down, but it comprised merely 1,000 people (Ishani, 2011). Similarly, in 2005, the Judges' Club, a union-like judges' organization, exerted pressure to impose integrity on elections (Wageeh, 2012). However, participants were mainly activists and intellectuals, and the movement failed to engage ordinary citizens.

Later movements did involve ordinary citizens. For instance, the largest of the laborers' movements was the El-Mahalla protest on April 6, 2008. It was the first uprising of such magnitude; however, it failed to penetrate beyond El-Mahalla. It did begin the "April 6 Youth Movement," which later played a major role in the January 25 revolution and utilized street and online activism (Ishani, 2011). Although this localized uprising was pivotal in the larger revolution, it did not reach the size needed to topple the Mubarak regime. Likewise, the National Coalition for Change, formed in 2010, had modest success in collecting signatures from people in support of the Change Declaration. The Declaration called for seven demands to achieve political transparency. However, because of the high risk of arrest, street collection of signatures was limited and the majority were online (Awad 2010).

To no avail, many individuals and groups made efforts to exert change. The challenge remained of coordinating the disjointed efforts and involving more citizens. The obstacle was organizing a critical mass movement capable of confronting the police. The role of cyberactivism in general, and the "We are all Khalid Said" Facebook page specifically were to fill in these voids.

\section{Cyberactivism}

Cyberactivism is defined as "the act of using the Internet to advance a political cause that is difficult to advance offline... The goal of such activism is often to create intellectually and emotionally compelling digital artifacts that tell stories of injustice, interpret history, and advocate for particular political outcomes" (Howard 2011, p.145). Web 2.0 refers to technology that allows user-generated content and enables users to interact and collaborate with one another. It includes SNSs, blogs, video-sharing sites and web applications to name a few. Citizen journalism or do-it-yourself (DIY), made possible by new technology, has enabled citizens to move beyond the role of the spectator to become players in the political game (Hirzallah, et al. 2011). A Facebook group page particularly brings together thousands of people with a common interest, transcending traditional boundaries. Moreover, "sharing" allows information to spread beyond the group (Samuels 2011).

\section{The "We are all Khalid Said" Facebook page}

The story of the brutal killing of the 28-year-old Alexandrian man Khalid Said spread on Facebook. Several days before he was killed, Said had shared online footage of police allegedly distributing confiscated drugs among themselves. On June 6, 2010, police dragged Said out of an Internet cafe and beat him to death. Pictures of his broken jaw and disfigured face were released by his family, shocking and enraging the Egyptian public. When the "We are all Khalid Said" page was set up on June 8, it demanded justice for Khalid and an end to police brutality.

\subsection{Page Administration}

The "We are all Khalid Said" Facebook page was founded by Wael Ghonim on June 8th. In the first two minutes, 300 people joined. Within one hour, 3000 people joined, and by the end of the day, the number of members reached 36,000. When within a few days, the number of members increased to 100,000, Wael Ghonim made Abdel Rahman Mansour a second director of the page (Ghonim 2012). On November 26, two days before the Egyptian parliamentary elections, the page was blocked by Facebook due to a false registration. After 12 hours Nadine Wahab, an Egyptian living in the U.S. and administrator of the English-language sister page, claimed ownership of the page. Days before the revolution, in anticipation of being arrested, Ghonim designated activists Ahmed Salah and Amr El Azaz as replacement administrators, for Abdel Rahman Mansour was serving in the military (Ghonim 2012). ${ }^{1}$

\subsection{The Silent Protests}

Following a member suggestion, the page, within a week of its construction, organized a "silent protest" to mourn the

\footnotetext{
1 There also had been another page formed in dedication to Khalid Said prior to the one constructed by Ghonim, but this page was likewise disabled in September 2010 because it was not owned by an individual, accountable person (Ghonim 2012).
} 
brutal death of Said. Members stood alongside the coast-side roads in the cities of Alexandria and Cairo, wearing black, silently facing the water with their backs to the street and the passers-by, and holding a copy of their holy books-be they Bibles or Korans. The strategy defied emergency law, which had existed for decades; among other restrictions, it bans public gatherings. The peacefulness of these innovative protests did not allow police to interfere (El-Hennawy 2010). With tens of people showing up, which was considered a success, the page organized silent protests in ten more cities. The second attracted several prominent opposition leaders, such as Dr. Mohamed El Baradei, Dr. Ayman Nour, Dr. Mohamed Ghoneim, Boussayna Kamel, and actor Khalid Abu ElNaga (Ghonim 2012, P150). These protests represented a rehearsal for turning cyberactivism into street action, overcoming the fear barrier.

\subsection{January 25 Mobilization}

On December 30, 2010, the "We are all Khalid Said" Facebook page created an event calling on its now 350,000 members strong to stand up against police misconduct on January 25-Police Day, a national holiday in Egypt honoring the police force. On January 15, encouraged by the outcome of the Tunisian revolution, the administrators titled the event "Revolution against torture, poverty, corruption and unemployment." The new title resonated with many members, and within four hours, 25,000 members had stated they were attending. By January 24, the number increased to 70,000 members. The page administrator coordinated, via email, with other leading activists, especially Ahmed Maher from the April 6 movement and Mostafa El-Naggar, one of the leaders of the presidential campaign of El-Baradei. The details were announced on the page three days before the event, which gave participants time to prepare but did not give the police time to confront them. Information included the date, time, locations, and telephone numbers of lawyers to call in the case of arrest (York, 2011). On January 25, Egypt witnessed the eruption of protests on a scale not seen before. Thousands of Egyptians took to the street nationwide on this epic day, demanding the ousting of the Mubarak regime and chanting "Bread, Freedom, Dignity."

The following is a number of signs that demonstrate the importance of "We are all Khalid Said" page in inciting action. 1) On the day following the uprising, 150,000 new members joined the page and looked to it for information, organization, and guidance (Ghonim 2012). 2) To avoid further online communication, the government of Egypt shut down the Internet and mobile phone services for the entire country on January 27, 2011. The blackout lasted almost one week, causing $\$ 90$ million in losses as estimated by the Organization for Economic Cooperation and Development (OECD) (Noble, 2011). Despite the tremendous loss, the government felt they could only regain control by shutting down access to online venues, the revolution's primary collaboration points. 3) Egyptian security robustly searched for the page administrator, arresting him on January 27 and detaining him for 12 days (Vargas 2012).

\section{Methodological Procedures}

\subsection{Research Questions}

Four research questions were developed, each corresponding to one particular mobilization theory, including the following: the culture mobilization theory, the strategic intervention theory, the social strain theory, and the resource mobilization theory. These four questions will frame the conversation to determine the online tactics driving citizens to revolt.

5.1.1 To what extent did "We are all Khalid Said" succeed in constructing a frame for injustice?

The culture mobilization theory argues that the success of mobilization depends on the movement's ability to create an injustice frame (Smelser 1962). To tackle this issue, the author examined content on the page to determine if the posts constructed a frame for injustice.

5.1.2 To what extent did "We are all Khalid Said" succeed in convincing members that many would join a mobilization effort?

The strategic intervention mobilization theory states that the success of mobilization depends on the ability to convince fellow citizens that the level of dissent in society is massive and that many will join the movement (De Mesquita 2010). The author examined the posts, comments, likes and other relevant details to investigate the ability of the page to communicate to its members that level of participation in a mobilization effort would be high.

5.1.3 To what extent did "We are all Khalid Said" succeed in persuading members that their collective action on January 25 would be well arranged?

The social strain theory offers a detailed explanation for the last step of the process - creating a well-organized action plan (Smelser 1962). The author examined all posts ranging from text, videos, photos, audio, polls, links, and events to inspect the page's ability to convince its members that the event was solidly arranged.

5.1.4 What resources did "We are all Khalid Said" have? 
The resource mobilization theory rationalizes that the success of mobilization depends on the ability of movement leaders to direct the resources needed to carry out a collective action (Hirzallah 2011; McCarthy, Zald 1977). The author examined whether the page, through means of digital technology, was able to overcome the issue of resources such as capital and labor.

\subsection{Determining Study Population and Sample}

The study population is all posts made on "We are all Khalid Said" Facebook page during the period between December 30, 2010 and January 25, 2011. December 30 is the date of the first call to take action on Police Day (January $25^{\text {th }}$ ), which became the first mass protest. The total number of posts examined is 132 posts.

\subsection{Categories of Analysis}

Categories were defined after carefully sifting through "We are all Khalid Said" posts. These include 1) Events, 2) Text (writing \& notes), 3) Photos, 4) Audio, 5) Video, 6) Polls, 7) Links. For analysis purposes, categories are further broken down into subcategories, which in turn are further broken into units of analysis. Below is a diagram illustrating the hierarchy between the classifications and the relationship between Categories and Subcategories?
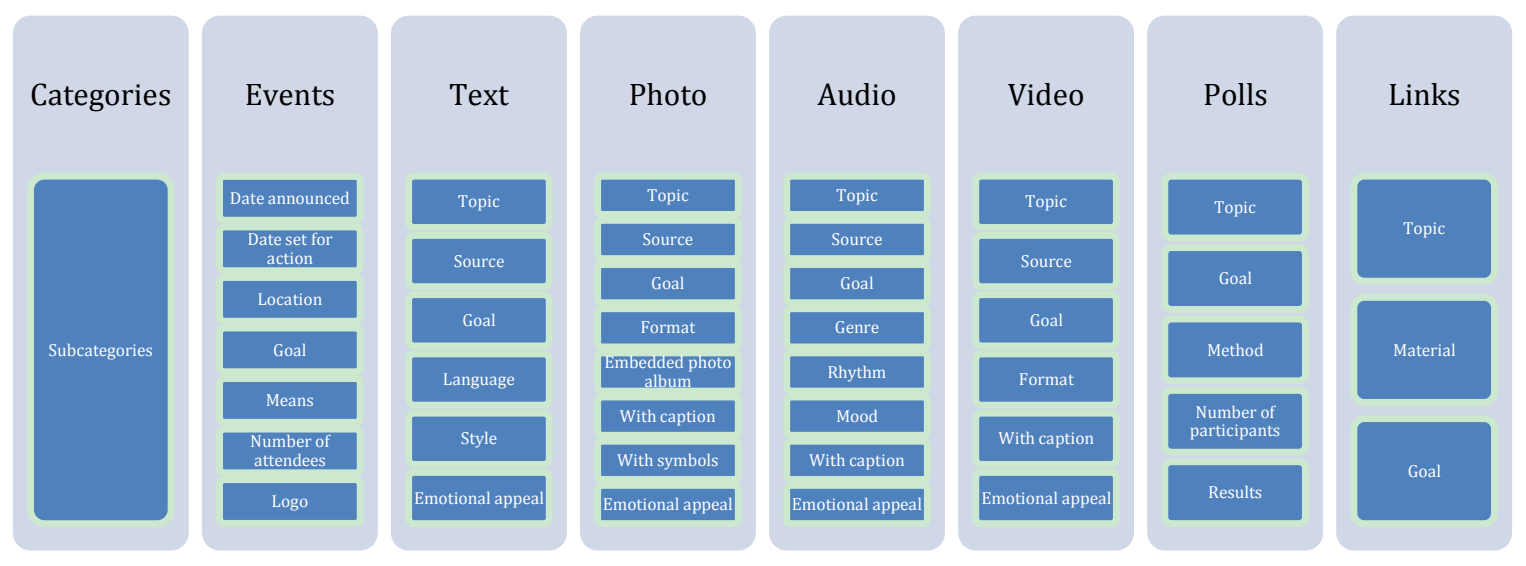

\subsection{Reliability}

The measure is reliable when it consistently gives the same answer each time analysis using the operational definitions is applied. Two independent coders were involved in the content analysis: the author and a Master's student who was trained by the author. Inter-coder reliability refers to the level of agreement among independent coders who code the same content using the same coding format. Holsti's formula was applied to measure the consistency of their findings.

$2 \mathrm{M}$

\section{Reliability:}

$$
\mathbf{N} 1+\mathbf{N} 2
$$

\section{$2(111)$}

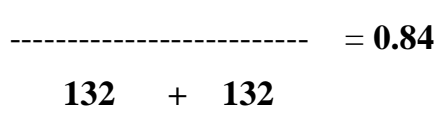

Where $\mathrm{M}$ refers to the number of times coders agree; $\mathrm{N} 1$ and $\mathrm{N} 2$ refer to the number of items coded by each coder. The resulting coefficient of 0.84 indicates an acceptable level of inter-coder reliability. (Lombard, M., Snyder-Duch, J., \& Bracken, C. C., 2002).

\section{Results}

\subsection{General Findings}

\subsubsection{Types of Posts}

From December 30 to January 25, "We are all Khalid Said" organized four events. The page created a total of 132 posts, combining words, visuals, and audio to influence its audience. They are the following: 42 writings $^{2}, 13$ notes, 36 videos, 32 photos, 3 and one song. It also used two polls to involve their audience in the decision-making and to test their

\footnotetext{
2 "Writing" refers to short pieces of text; if writing exceeds 420 characters, it is turned automatically into a "note."

3 The number 32 refers to the number of photos appearing on the wall, but clicking on these photos leads to other sets of photos, for a total of 152 photos.
} 
acceptance of its message. In two instances, the page used links to other websites to build rapport with other groups with shared goals. The average number of likes per post was (1,229); the average number of comments was (303); the average number of views was $(97,163)$.

\subsubsection{Timeline of Posts}

Tracing the timeline of posts on "We are all Khalid Said", January 1st (10 posts), January 15 (12 posts), January 24 (16 posts), and January 25 (18 posts) stood out, as typically the page created three to four posts a day. While the first two dates represented mere reactions to occurring events, the last two dates represented attempts to mobilize a future event. The evening of December 31 marked the day Saints Church of Alexandria was the target of a deadly terrorist attack. On January 1, the page's members shared writings, notes, videos, and photos, and they created an event, a silent stand in solidarity with the victims, to be conducted the following week. January 15 marked the day President Bin Ali of Tunisia fled the country. The page responded with an unprecedented number of posts, 12 in total. Posts made on January 24 served to mobilize page members with a total of 10 videos in one day. January 25 was the day with the highest number of posts, used to recount developments of the day and to mobilize for the January 28 protests, the Day of Rage. This data demonstrates that there is a direct correlation between the intensity of events and the intensity of Facebook activity.

\subsubsection{Topics Discussed}

In the 27 days prior to the revolution, one fourth of the posts directly called for an uprising. Other posts pushed indirectly for the uprising - comparing the situation in Egypt with that in Tunisia or highlighting problems such as police brutality and poor living conditions and offering uprising as the solution. The bombing of Saints Church was cited as proof that the government was incompetent and that Egyptians needed to intervene before their country fell into sectarian violence. It is worth noting that the administrators of the page had members participate in the decision-making. In the course of one month, administrators asked page members eight times to critique how the page was run and to offer suggestions. By setting an example of how Egyptians could work together and by emphasizing unity, administrators were able to establish trust among the members of the "We are all Khalid Said," which would be important to later convince that their "friends" from the page will go with you to the streets.

\subsubsection{Source of Posts}

Almost half the posts $(45 \%)$ on the page were either made by members of the page or shared from other pages. Posting of members' contributions communicated a number of messages. First, it allowed members to exercise citizen journalism, as $37.5 \%$ of photos and $33.3 \%$ of videos were generated by page members. Second, it communicated respect to page members, as it proved that the page took its audience seriously. Third, it recognized those with significant participation, as their comment could be selected out of the hundreds and made into a post. Fourth, highlighting a member comment expressed a view shared by several members, either building mainstream opinion or refuting arguments repeated by a different group.

The posting of other material available on the Internet also strengthened the argument and gave it credibility. First, it showed that their message was widely shared by not only ordinary citizens but also reputable public figures. Second, it showed that the administrators did not look for personal recognition but were willing to cooperate with all other online administrators to achieve a common goal. Third, it allowed the page administrators to make use of available exterior resources and not limit themselves to content produced by just their page members.

\subsubsection{Goal of Posts}

Each post communicated a unique message with an underlining goal. Goals varied between persuading (37\%), providing information (30\%), calling for action (22\%), or expressing opinions/feelings (11\%). Additionally, polls were conducted on the page, communicating a genuine desire to gather accurate information. The sharing of texts, videos, and photos that contained information versus emotion shows interest in educating members. While administrators expressed their opinions about an issue, they did not try to impose a particular view. This not only opened discussion amongst administrators and members, but also helped erase any hierarchy. Additionally, almost $20 \%$ of posts directly called for people to take action.

\subsection{Detailed Findings}

\subsubsection{Event analysis}

The "We are all Khalid Said" page announced four events during this window of time, having explicit goals, means, and styles. The first event was announced on December 30 and set for January 25 . The stated goal was to reject police brutality, and it was thrown to "test the waters." It left many details unsettled and many details to be determined by page members, such as the nature of the action to take to express this rejection of police actions.

The second event was announced January 1, 2011 and set for January 7. The goal stated was to express solidarity with 
victims of the Saints church bombings. In the second event, all decisions regarding meeting time and locations were made by administrators of the page. Members determined that the call to action would be a silent stand. To get members on board, administrators added the following links: a "Note," a "Video," and a "Photo Album." The number of page members stating they would be attending the event was more than 15,000 .

In the third event, most details were arranged by page administrators, except for a few left out to mislead the police. (This publicly withheld information was communicated to select members privately.) The event was announced on January 14 and set for January 25 th. The goal was to combat corruption, injustice, unemployment and torture. The action called for to achieve this goal was an uprising. More than 70,000 page members stated they were attending.

The final event was announced on January 25 and set for January 28. The meeting points announced - "all mosques and churches"- were both specific, as all protestors can find them, and vague, as they were too broad for police to locate. The goal was to change the regime through the means of a revolution. More than 18,000 members stated they were attending before the Internet was cut off in all of Egypt, two days after the event was announced. For more information, please see Appendix.

\subsubsection{Textual Analysis: Writing and Notes}

Textual posts added up to 55 posts. A number of 42 textual posts were "writing," i.e. less than (420) characters, and 15 were "notes," i.e. more than (420) characters.

6.2.2.1 Topic of text. Topics discussed were: uprising (34.5\%); administration of the page (10.9\%); Tunisia, the Saints church bombing, and police (9\% each); suicide and unity (5.5\% each); the New Year and change (3.6\% each): justice, the blocking of Facebook and Twitter, media coverage, the silent stand, and a farewell letter (1.8\% each).

The majority of notes touched on the same issues as the writings, but in much more detail. When addressing the issue of Tunisia, the only note included a recount of the Tunisian revolution, from the day Abu Azizi set himself on fire to the day the Tunisian president Bin Ali fled the country. When addressing the Saints church bombing, all notes included in-depth information, such as the names of the victims, their age, and some information about them.

6.2.2.2 Language used. The "We are all Khalid Said" page mainly used Egyptian slang (78.2\%), but the page treated a note much more formally than writing. While classical Arabic constituted less than $15 \%$ of writing, it constituted almost $40 \%$ of notes. Foreign language was also used. One note, originally a member comment, was posted in English along with its translation.

6.2.2.3 Style of text. Sharing a news item, a joke, or an anecdote; making a statement or asking a question - administrators used a variety of styles, adding vitality to the page. In notes, press releases and member letters were most often used. While press releases were the most effective way to inform, letters were the most moving, as they were the most personal of the styles. For instance, the last note ever made was a farewell letter written by Wael Ghonim. The letter was heartbreaking. In one day, 1280 comments and thousands of likes had appeared on the note. This outpouring of responses displayed the member's emotional connection to the "admin" and concern that he might be arrested, injured, or even killed. Also, the thought that the page on which they spent hours daily might cease to exist caused a lot of distress for members.

6.2.2.4 Emotional Appeal in Text. The ratio of logical appeal to emotional appeal was about one fourth of all writing posts and one third of all note posts. With regard to emotional appeal, the "We are all Khalid Said" page tried to provoke several emotions, particularly hope, determination, and solidarity. It is remarked that the page relied on positive emotions more than it relied on negative emotions such as anger and remorse. Positive emotions made up $77.5 \%$ of all the emotional appeals. Moving content toward positive emotions rather than feelings of despair, anger, or revenge might be one reason why Egyptians conducted a peaceful revolution.

\subsubsection{Photo Analysis}

6.2.3.1 Topic of photo. Photos and text were used to supplement each other rather than replicate the message, as the topics highlighted differed in the two mediums. For instance, a number of visual aids were used to demonstrate to members how to invite friends, advertise the page, and diffuse information about January 25 among popular web pages and blogs. Silent stands and the Saints Church bombing were the subject of close to half the photos versus only $11 \%$ of corresponding textual posts. Of the photos, $34 \%$ portrayed acts of solidarity compared to the $5.5 \%$ that addressed unity in textual posts. On the other hand, uprising was the main topic in textual posts; in photos it was the third most popular. Despite the horrible conditions Egypt was living under and a deadly terrorist attack of the Saints Church bombing, graphic photos represented only $15.6 \%$ of all photos. This shows that the page tried to maintain a mild tone.

6.2.3.2 Photo Format. The majority of photos published on the wall were linked to an entire album of 152 photos during the surveyed period. Of the 32 photos examined, $56 \%$ were of people. Aside from those portraying the bombing victims, 
these photos typically portrayed ordinary people protesting. This sent the message to the members of the page who were afraid to take their activism to the streets that protesting is possible and others would support you. Surprisingly, one quarter of the photos were images of text. One possible explanation for such posts is that when text is posted as a photo, it is more accentuated and easier to share. Another explanation is that due to a lack of resources, administrators were substituting artworks. Other formats of photos included composite photos (9\%), caricature, graph, and newspaper headline ( $3 \%$ each).

6.2.3.3 Presence of Caption and Symbols. All photos were accompanied by captions; almost half of which (44\%) recognized virtuous acts and attempted to inspire others. The other half of captions $(56 \%)$ was equally divided between calls for action or expressions of anger and remorse. In addition, a number of photos were accompanied by symbols $(41 \%)$. The majority of those symbols (62\%) were signs of patriotism (such as the Egyptian flag) and of unity (such as a 'hugging' cross and a crescent). Aside from that, the color black was used to symbolize grief, either over Khalid Said or the victims of the church bombing.

6.2.3.4 Emotional Appeal in Photos. More than two thirds (69\%) of communicated emotional appeals were positive. For instance, almost one third of the photos portrayed Egyptians acting collectively and standing in solidarity with one another. Another third communicated determination and patriotism, as they portrayed Egyptians carrying Egyptian (and Tunisian) flags and leaflets saying they would go to the streets on Jan 25th. The final third (31\%) showed victims of the church bombing attack and other violations of human rights, stirring negative emotions such as anger, remorse, and sarcasm. However, setting off negative emotions was a natural result of events rather than an intentional incitement by the page, as it focused on positive emotions.

\subsubsection{Audio Analysis}

"We are all Khalid Said" utilized only one vocal piece: a song. With a Spanish rhythm and an upbeat mood, the song talked of a bright future. The song provoked action through an emotional appeal, highlighting youth's determination and capabilities, again presenting positive emotions

\subsubsection{Video Analysis}

6.2.5.1 Topic of Video. Videos tackled a number of topics: uprising (30.5\%), Tunisia (19.4\%), oppressive Egyptian conditions (13.9\%), unity (11.1\%), the Saints church bombing (8.3\%), Egyptian patriotism (5.6\%), and morality, suicide, calls for a peaceful protest, and aspirations for a better future $(2.8 \%$ each). With regard to the material, activities of solidarity appeared in one third of videos. Graphic material, such as dead bodies, injuries, torture, crime victims, and blood, appeared in one fourth of the videos. Visual aids, such as animation, graphs, and writing, appeared in two videos.

To mobilize for the uprising, the page relied mainly on text and video, as the uprising was the number-one ranked topic for both, representing in itself about one third of all textual and video posts. When covering past activities by page, photos - more than videos or text-were used to document events. The topic of Tunisia ranked second in video posts. Finally, the topic of "oppressive Egyptian conditions" was covered in video posts but ignored in text and photos.

6.2.5.2 Video Format. Videos were strong methods of mobilization. The page used a variety of video formats. The format used the most was of real footage of Egyptians or Tunisians defying the ruling regime (47.2\%). Of these, 53\% were edited and $47 \%$ were raw footage. The second format was music videos that use patriotic songs with touching lyrics to incite members and steer their emotions (22.2\%). The third format was webcasts portraying activists or politicians talking logically to the Egyptian public, and pointing to the necessity of taking action and urging them to go to the streets on Jan 25 (16.7\%). Other formats included TV programs (11.1\%) and an animated film (2.8\%). Each of these videos included a caption that reiterated the message.

6.2.5.3 Emotional Appeals in Videos. As with text and photos, the majority of videos incited positive emotions (66.7\%). The positive appeals communicated the most were that of determination (13.9\%) and Tunisian admiration (11.1\%). Others included: patriotism, solidarity, and sympathy ( $8.3 \%$ each), humor and optimism (5.6\% each), provocation and change (2.8\% each). The negative emotional appeal communicated the most was that of anguish (13.9\%). Other negative appeals included anger (11.1\%), sarcasm $(5.6 \%)$, and blame $(2.8 \%)$.

Videos provoked a wider variety of emotions; 13 different types of emotions in comparison to ten in text and photos eight in photos. Emotions communicated in videos, but not in text or photos, were provocation, anguish, and aspiration for change. One particularly provocative video was considered to have had a strong effect. In this video, Asmaa Mahfouz, who later became an icon for the revolution, called those who are afraid to stand up to injustice "cowards." Moreover, she challenged males in particular as she pointed out that women like herself are braver than a lot of men.

\subsubsection{Poll Analysis}

Polls are a manifestation of democratic practices, as decisions drawn from polls are taken bottom-up. The page, in less 
than a month's time, conducted two polls. The first addressed the way the page is administrated, and the second addressed details regarding the silent stand in support of victims of the Saints Church bombing. The goal of the first poll was to address complaints and improve the way the page is run, and it used open-ended questions. The poll had 918 responses and 1301 likes. The goal of the second poll was to decide on the location, date, and time to carry out the silent stand. It used closed-ended questions. The author was unable to retrieve the number of participants. The polls show an interest in collective decisions, and the high rate of responses shows a great deal of member involvement.

\subsubsection{Link Analysis}

The page also incorporated two outside links. The first was a link to a newspaper article, discussing a cabinet meeting in anticipation of January 25th. This link served to show that the government was fearful. The second link was to a Google spreadsheet, in which members were invited to write their emails. The goal was to create an alternative way to reach members in case of government blockage of Facebook. Utilizing these links illustrates hybridity. Software processes, patterns of information circulation, and communicative and social practices have hindered government ability to censor information or to prevent members from networking with each other. This realization led the Egyptian government to cut off all service on January 27th.

\section{Analysis of Results}

The role Facebook, and particularly the "We are all Khalid Said" page played was to mobilize previously inactive people. The content analysis demonstrates the process through which the "We are all Khalid Said" Facebook page managed to create the critical mass of protesters. The process entailed five missions: creating a frame of injustice, broadcasting activities of defiance, inspiring members, engaging members, and coordinating an action plan.

\subsection{Creating a frame of Injustice}

The page shared rational and emotionally compelling digital artifacts that tell stories of injustice. Short writings, long notes, photos and videos all revolved on the oppressive living conditions in Egypt. These included both the major events that resulted in the loss of lives and general poverty, corruption, and unemployment.

\subsection{Broadcasting activities of Defiance}

The page encouraged members to upload text, photos, and videos that document their effort to challenge the regime. Members posted photos of themselves holding signs expressing resentment of the regime. As citizen journalists, they reported on events such as the 'silent protests.' The page also posted documentaries on successful revolutions in Tunisia and Chile.

\subsection{Inspiring Members}

The page acted as a source of inspiration. First, the page mediated between its members and supported their ideas and actions. Second, the page used text, photos, audio, and videos to steer a number of emotions. On one hand, it raised feelings of hope, determination, and solidarity and on the other hand it provoked feelings of anger, remorse, and agony. By the time January 25 arrived, members were emotionally charged enough to accept taking an action.

\subsection{Engaging Members}

The page provided a means for people to find and associate with others of similar political views. By conducting polls and opening up discussions, the page got its members involved in the decision-making. One example is the back-and-forth discussions in the postings and comments about goals and methods of the protests. Moreover, page administrators would regularly designate tasks for members, such as calling media outlets, sharing posts on blogs, and printing and passing out leaflets. The page was transformed from a forum on which participants express opinions and vent emotions to a forum on which participants take actions.

\subsection{Coordinating an Action Plan}

On January 15 , the page organized an event calling for an uprising on January $25^{\text {th }}$. As mentioned previously, the page announced details three days before the event. The page also gave members a number of guidelines to follow such as: hold Egyptian flags only, no political emblems, no violence, don't disrupt traffic, wear running shoes, bring plenty of water, and don't bring your national ID card. The page also provided a list of telephone numbers of lawyers and human rights organization as a precautious measure in case of arrest.

\section{Discussion}

The success of political mobilization depends on the ability of people to come together. In the digital era, social media substitutes the physical surroundings and allows people beyond their immediate environment to connect. While these meetings are virtual, they still provide participants an outlet to exchange ideas and coalesce.

Social media in Egypt satisfied most mobilization conditions defined in social movement theories. The "We are all 
Khalid Said" page was created to bring attention to the compelling story of Khalid Said as a starting point to defend all aspects of human rights in Egypt, posting stories, photos and videos featuring humiliation, torture, poverty, and misery. The culture mobilization theory argues that to succeed at mobilizing individuals, social movements need to create an injustice frame. An injustice frame entails ideas and symbols that demonstrate the significance of the problems and how the movement will address them (Smelser 1962). The "We are all Khalid Said" page focused on topics of police brutality, oppressive conditions, and government negligence that led to the deadly terrorist attack that killed and injured many Egyptians. The page incorporated a number of symbols including: black to mourn the terrorist attack victims; Khalid Said and Sayed Belal as victims of police brutality; and the Egyptian flag and a combined cross and crescent, symbolizing unity among Egyptian Muslims and Christians.

The page's call to take a stand against "torture, corruption, poverty and unemployment" resonated with many young Egyptians. It succeeded in grouping thousands of people who shared the same discontent in a friendly respectful environment. The page voice was that of a friend. About $86 \%$ of the subcategory of "writing" utilized Egyptian slang and has always maintained a mild tone. It is a voice that echoes that of many people who share the same views and feelings. The page members grew by the day; within six months of its creation, the number of members reached more than 360,000 . On average, the number of likes to a posting exceeded 1,200 , the number of comments exceeded 300 , and the number of views exceeded 97,000 (Ghoneim, 2012).

According to the strategic intervention mobilization theory, in order for the mobilization process to succeed, activists have to convince their fellow citizens that the level of dissent in society is pervasive, so that they will join the movement (De Mesquita 2010). One of the features of Facebook is that it shows how many members are enrolled in the page, so members can see their numbers increase. Moreover, administrators of the page would occasionally point out this increase. For instance, a post by one administrator on January 8, 2011, reads:

"Thank God we are now 365,000 members on the page, and within the last 30 days, 60 million people have viewed our writings and more than 300,000 comments and likes have been made on content. Please help us spread the word about the page, because the faster our voice reaches people, the more capable we will be to make the case of a victimized Egyptian, a public opinion issue and collectively work on solving it."

The strategic intervention mobilization theory rationalizes that the larger the number of citizens that are willing to join a movement, the more likely it is to succeed, especially with the allocation of an appropriate action plan. If people agree with the proposition, they people will be mobilized to provide support (De Mesquita 2010).

The social strain theory, also known as value-added theory, offers a more detailed explanation for the mobilization process. The social strain theory proposes six factors that encourage the building of social movements: 1) Structural conduciveness: people come to believe that their society has problems. 2) Structural strain: people experience deprivation. 3) Growth and spread of a solution: a solution is proposed to address the problems people are experiencing, and it spreads. 4) Precipitating factors: discontent usually requires a catalyst (often a specific event) to transform it into a social movement. 5) Lack of social control: the regime that is the target of the proposed change must allow a minimum level of free communication; if the social movement is swiftly and brutally repressed, it may never materialize. 6) Mobilization: this is the actual organizing and active component of the movement (Smelser 1962).

With regard to the first and second factors, as formerly mentioned, the majority of "We are all Khalid Said" members shared the belief that their society had problems and had either experienced deprivation or strongly empathized with those who did. The third factor is the growth and spread of a solution. The news about the success of the Tunisian revolution and the flight of the Tunisian president shook people across the Arab world. Administrators and members of "We are all Khalid Said" followed events in Tunisia with admiration and inspiration. The solution was revealed: follow Tunisia's example and revolt. Administrators and members had refrained from writing words such as "revolution," "uprising," or "demonstration," fearful of police surveillance. Instead, they cited two simple words "El-Egaba Tunis," i.e., "The answer is Tunis." The meaning was clear: Egyptians need to topple the regime just like Tunisians did.

The Forth factor is the presence of a catalyst. Many disturbing events had occurred in the buildup toward the revolution, from the killing of Khalid Said, to the killing of Egyptians in a church on New Year's Eve, to the killing of Sayed Bilal, who was wrongly accused of the bombing, to the self-immolation of Mohamed Abu Azizi in Tunisia, to four attempts at self-immolation by Egyptians inspired by Abu Azizi. Egypt experienced a surplus of catalysts.

The fifth factor is the lack of social control. People in power in Egypt are mostly between 60 and 80 years of age. This age divide was beneficial as these older leaders generally took the youth and their new ways lightly. The danger from online activism was inconceivable to them. This gap between those in power and youth allowed them some flexibility to maneuver. 
The sixth factor is mobilization, or the actual organization of the movement. Administrators of "We are all Khalid Said" announced the time and location points, slogans to be chanted, telephone numbers of lawyers who volunteered to help protestors in case of arrests, and many tips on how to protect oneself. The page prepared members as best as it could for the challenging day.

It is important to note that "We are all Khalid Said" coordinated with other activists and political groups. The resource mobilization theory states that successful mobilization depends on movement leaders' control over the resources needed to take collective action. Some of the important issues to consider are what resources the group controls prior to mobilization, the processes by which the group marshals and directs resources towards social change, and the degree to which people outside the group can enhance those resources (Hirzallah 2011; McCarthy, Zald 1977). One of the important aspects of this theory is the availability of resources, i.e. money and labor. The value of Facebook lies in its ability to reach out to millions of people at a free cost. As for labor, occasionally, "We are all Khalid Said" would ask members to do certain tasks, such as inviting friends to events, publicizing the page on popular web pages and blogs, sharing posts on personal pages, etc. As the buildup for the revolution intensified, administrators asked willing members to risk taking the online material to the streets. Another aspect of the Resource mobilization theory is the ability to get support from individuals and organizations outside that represented by the social movement. The page frequently announced coordination with other activists and political groups such as the "April $6^{\text {th }}$ ' movement. "We are all Khalid Said" has introduced another Facebook page "RASD," which aimed at reporting news in order to facilitate the flow of information especially the developments on January 25th.

Another important aspect of the resource mobilization theory is the costs and rewards involved. January 25 protestors knew they were taking major risks, but as they expressed on the page, they had high aspirations and thought the rewards were worth the risk. An encouraging factor might have been the increasing number of people stating they were attending the event. Put simply, the bigger the number of protestors, the smaller the risk. The number of attendees increased by the minute from one thousand, to two thousand, to five thousand, to ten thousand, twenty, thirty, until it exceeded seventy thousand, an imaginary number for many.

\section{Conclusion}

The question communication scholars mostly ask is whether the revolution on January 25 could have happened in the absence of Facebook. A critical mass can be formed in various ways, such as gatherings taking place at universities, community centers, and factories. In the case of the Egyptian revolution, the critical mass was mainly achieved online. Activists working on the ground played an important role in defining the meeting points and leading protests, but their ability to reach followers was limited due to government crackdowns. Technology eliminated the need to be physically present and allowed participants to form a public opinion and plan a collective action. Cyberactivism provided a safe haven for youth who aspired to create change. Moreover, social media's hybridity features blurred the line between activists and sideliners, bringing in those who would otherwise have been politically apathetic.

The administrators of the "We are all Khalid Said" Facebook page were successful in attracting many young people through cyberactivism. Administrators implemented a process with five key missions: 1) Creating an injustice frame, 2) Broadcasting activities of defiance, 3) Emotionally inflaming and inspiring people, 4) Engaging participants, and 5) Organizing a concerted action plan. First, social media were more capable than any other media of creating this injustice frame, as they could combine and share several types of artifacts. Second, social media played an important role in broadcasting acts of defiance to information-seekers looking for an alternative to mainstream media. While mainstream media partially or completely overlooked defiance, social media highlighted and glorified them. Third, social media were best in emotionally charging people. Members' reactions were amplified as they read each other's comments portraying unjust conditions or heroic actions of fellow citizens. Bearing witness to these furious reactions deepened the members' anger while celebrating the heroic actions of defiance inspired members to emulate them. Fourth, social media was particularly important in engaging participants. "We are all Khalid Said" administrators conducted polls, opened up discussions, and designated tasks for members, as they gradually face their fear of government backlash. Lastly, social media was most efficient in spreading the details of the scheduled revolution through channels that were safer, faster, and more far-reaching than any other means of communication. The mobilization thrived because of the achievements of these five missions.

The Egyptian revolution has further validated the four discussed mobilization theories: 1) Culture mobilization theory, 2) Social strain theory, 3) Strategic intervention mobilization theory and 4) Resource mobilization theory. First, by bringing attention to the brutal killing of Khalid Said, social media created an injustice frame. This epitomizes the culture mobilization theory by putting injustice at the heart of the movement. Second, the social strain theory proposes six factors that encourage the building of social movements, including minimum level of free communication and the ability to organize a workable plan. Communication via social media was conducted with an adequate level of freedom. 
For the first time, people dared to propose a drastic solution: the complete toppling of the regime. To actualize the toppling of the regime organizers utilized social media to coordinate a strategic plan. Third, social media accentuated the level of dissent. Facebook allowed users to monitor the number of views, likes, shares of posts, and the increasing number of members. These numbers were mounting on "We are all Khalid Said" by the day. This corresponds directly with Strategic intervention mobilization theory, which stresses the need for the protestor to feel that discontent is pervasive, and that they are backed by the people. Fourth, the resource mobilization theory considers the amount of resources available to movement leaders. Social media enabled the activists to reach millions of people at nearly no cost. These four theories outline the framework by which the mobilization developed.

This research empirically proves that cyberactivism taking place on "We are all Khalid Said" successfully formed a critical mass large enough to spark an uprising. The Egyptian revolution of January 25 represents an undisputed truth that online activity can in fact incite political mobilization. Social media engages a far reach of citizens and empowers individuals to express, unify, and collaborate to defend a common goal. The role social media played in Egypt changed the history of the entire nation. Social media has and will continue to play a pivotal role in revolutions to come.

\section{Acknowledgments}

My deepest gratitude is due to Alia Nagm and Cynthia Hamilton who assisted in editing and critiquing this manuscript.

\section{References}

Anon. (2011). Social media, cell phone video fuel Arab protests. The Independent. http://www.independent.co.uk/life-style/gadgets-and-tech/social-media-cellphone-video-fuel-arab-protests-222708 8.html.

Awad, M. (2010). ElBaradei urges Egypt vote boycott, foresees change. Reuters. http://www.reuters.com/article/2010/09/07/ozatp-egypt-elbaradei-idAFJOE68602L20100907

Carpenter, C. A. (2010). The Obamachine: Technopolitics 2.0. Journal of Information Technology \& Politics, 7, 216225.

De, M., \& Ethan, B. (2010). Regime change and revolutionary entrepreneurs, American Political Science Review, 104(3).

El-Hennawy, N. (2010). We are all Khalid Said: Redefining political demonstration in Egypt. Egypt Independent. http://www.egyptindependent.com/news/we-are-all-Khalid-saeed-redefining-political-demonstration-egypt

Eg25January TV (2011, May 5). Gamal Mubarak Ridicules Facebook Youth Before the Revolution. Retrieved January 15, 2014 from https://www.youtube.com/watch?v=NwtgqRRQilA

Ghonim, W. (2012). Revolution 2.0: The Power of the People Is Greater Than the People in Power: A Memoir. Boston: Houghton Mifflin Harcourt.

Howard, P. N. (2011). The Digital Origins of Dictatorship and Democracy: Information Technology and Political Islam. Oxford: Oxford University Press.

Hirzalla, Fadi; Van Zoonen, Liesbet; de Ridder, Jan. (2011). Internet use and political participation: Reflections on the mobilization/normalization controversy, Information Society, 27(1), 1-15.

Ishani, M. (2011). The hopeful network. Foreign Policy. http://www.foreignpolicy.com/articles/2011/02/07/the_hopeful_network-2

Khamis, S., \& Vaughn, K. (2011). Cyberactivism in the Egyptian revolution: How civic engagement and citizen journalism tilted the balance. Arab Media and Society, 14, 1-37.

Khamis, S., \& Vaughn, K. (2011). 'We Are All Khalid Said': The potentials and limitations of cyberactivism in triggering public mobilization and promoting political change. Journal of Arab \& Muslim Media Research, 4(2-3), 145-163. http://dx.doi.org/10.1386/jammr.4.2-3.145_1

Langlois, G., Elmer, G., Mckelvey, F., \& Devereux, Z. (2009). Networked Publics: The Double Articulation of Code and Politics On Facebook. Canadian Journal of Communication, 34, 415-434.

Lombard, M., Snyder-Duch, J., \& Bracken, C. C. (2002). Content analysis in mass communication: Assessment and reporting of intercoder reliability. Human Communication Research, 28, 587-604.

March Group (2009). Summary of the Activities of the University Autonomy Group "9 March” until August 2008. [Pamphlet]. Cairo, Egypt.

Noble, C. (2011). Communications block cost Egypt $\$ 90$ million - OECD. Market Watch. http://www.marketwatch.com/story/communications-block-cost-egypt-90-mln-oecd-2011-02-03 
Samuels, B. (2011). Facebook, Twitter, You Tube--And Democracy. Academe, 97(4).

Smelser, N. J. (1962). Theory of Collective Behavior. New York: Free Press.

Vargas, J. A. (2012). Spring Awakening: How an Egyptian Revolution Began on Facebook. The New York Times. http://www.nytimes.com/2012/02/19/books/review/how-an-egyptian-revolution-began-onfacebook.html?pagewant ed=all\& $\mathrm{r}=0$

Wageeh, T. (2012). The Judges Club: Seventy Years of Victories and Debacles. Almasry Alyoum. http://www.almasryalyoum.com/news/details/151533\#

York, J. (2011). The Revolutionary Force of Facebook and Twitter. Nieman Reports, 65(3), 49-50. 


\section{Appendix}

Events Announced

\begin{tabular}{|c|c|c|c|c|}
\hline Event Title & $\begin{array}{l}\text { Celebrating } \\
\text { Egyptian } \\
\text { Police Day } \\
\text { (in our way)- } \\
\text { January } 25\end{array}$ & $\begin{array}{l}\text { Silent Stand in Black } \\
\text { Clothes Mourning } \\
\text { Victims of Terrorism }\end{array}$ & $\begin{array}{c}\text { January 25- } \\
\text { Revolution against } \\
\text { Torture, Poverty, } \\
\text { Corruption and } \\
\text { Unemployment. }\end{array}$ & $\begin{array}{c}\text { The Friday of Anger- } \\
\text { Revolution against } \\
\text { Corruption, Injustice, } \\
\text { Torture, and } \\
\text { Unemployment }\end{array}$ \\
\hline $\begin{array}{l}\text { Date } \\
\text { announced }\end{array}$ & Dec 30, 2010 & Jan 1,2011 & $\begin{array}{c}\text { Jan 14, } 2011 \\
\text { (Editing of Dec } 30 \\
\text { Event) }\end{array}$ & $\begin{array}{c}\text { January 25, } 2011 \\
\text { (Editing of Jan } 14 \text { Event) }\end{array}$ \\
\hline $\begin{array}{l}\text { Date set for } \\
\text { action }\end{array}$ & January 25 & January 7 & January 25 & January 28 \\
\hline Location & Undetermined & $\begin{array}{c}\text { All of Egypt } \\
\text { Meeting points: } \\
\text { Identified locations in } \\
18 \text { Governorates }{ }^{4}\end{array}$ & $\begin{array}{c}\text { All of Egypt } \\
\text { Meeting Points: } \\
\text { Identified \& unidentified } \\
\text { locations in } 18 \\
\text { governorates } \\
\end{array}$ & $\begin{array}{c}\text { All of Egypt } \\
\text { Meeting points: } \\
\text { Mosques and churches }\end{array}$ \\
\hline Goal & $\begin{array}{l}\text { Rejecting } \\
\text { police } \\
\text { brutality }\end{array}$ & Expressing solidarity & $\begin{array}{l}\text { Combating corruption, } \\
\text { injustice, unemployment } \\
\text { and torture. }\end{array}$ & Regime change \\
\hline Means & $\begin{array}{c}\text { Open for } \\
\text { members' ideas }\end{array}$ & Silent Stand & Uprising & Revolution \\
\hline $\begin{array}{l}\text { Event page } \\
\text { encompasses }\end{array}$ & $\begin{array}{l}\text { Unable } \\
\text { to retrieve }\end{array}$ & $\begin{array}{l}\text { Link to Note } \\
\text { (Location of stands) } \\
\text { Link to Video } \\
\text { (Invitation to a stand) } \\
\text { Link to Album } \\
\text { (The silent stand) }\end{array}$ & Unable to retrieve & No links \\
\hline $\begin{array}{l}\text { No of members } \\
\text { stating they } \\
\text { are Attending }\end{array}$ & None & More than 15,000 & More than 70,000 & $\begin{array}{c}\text { More than } 18,000 \\
\text { (Before Internet was } \\
\text { blocked) }\end{array}$ \\
\hline Logo & $\begin{array}{l}\text { Unable to } \\
\text { retrieve }\end{array}$ & & & \\
\hline
\end{tabular}

\section{(c) $\mathbf{E Y}$}

This work is licensed under a Creative Commons Attribution 3.0 License.

${ }^{4}$ Egypt encompasses 29 governorates. 